\title{
A EDUCAÇÃO COMO MEIO PARA ALCANÇAR UMA PRESENÇA EQUILIBRADA ENTRE MULHERES E HOMENS NA POLÍTICA
}

\section{THE EDUCATION AS A MEANS TO ACHIEVE A BALANCED PRESENCE OF WOMEN AND MEN IN POLITICS}

\author{
Vicente Bandeira de Aquino Neto ${ }^{1}$ \\ Thalyany Alves Leite ${ }^{2}$
}

\section{RESUMO}

Por meio deste artigo mostra-se que as políticas governamentais que buscaram igualar sexogênero na representação política são ineficientes e incapazes de reverter um quadro de desigualdade em escala mundial. Analisa-se a necessidade de ruptura com o modelo clássico de deliberação política, que hierarquiza sexo-gênero, levando a uma desproporção na representação feminina em comparação à masculina nos cargos políticos. Aponta à educação como meio capaz de alcançar um equilíbrio entre a presença feminina e masculina na política, sendo necessário o enfrentamento da discriminação estrutural da política brasileira, que exclui a mulher da vida pública, em evidente enfraquecimento da legitimidade democrática.

Palavras-Chave: Política. Mulher. Educação. Gênero. Igualdade. Efetividade.

\begin{abstract}
Through this article it is shown government policies that sought to match sex-gender in political representation are inefficient and unable to reverse a global inequality picture. We analyze the need to break with the classical model of political deliberation, which hierarchizes sex-gender, leading to a disproportion in female representation compared to male representation in political positions. It points to education as a means capable of achieving a balance between the female and male presence in politics, and it is necessary to confront the structural discrimination of Brazilian politics, which excludes women from public life, in evident weakening of democratic legitimacy.
\end{abstract}

Keywords: Politics. Woman. Education. Gender. Equality. Effectiveness.

\footnotetext{
${ }^{1}$ Doutorando em Direito Constitucional pela Universidade de Fortaleza - Unifor, (Brasil). Advogado Eleitoral.

${ }^{2}$ Doutoranda em Direito Constitucional pela Universidade de Fortaleza- Unifor, (Brasil). Advogada. E-mail: thalyany@yahoo.com.br
} 


\section{INTRODUÇÃO}

A Educação como meio para se alcançar uma presença equilibrada entre mulheres e homens na política é o tema que orienta o presente estudo. Intenta, estimular a discussão acerca do reflexo direto na concretização de um modelo de democracia preocupada em promover a inclusão da mulher no processo de deliberação política a partir da educação. A condição da mulher na sociedade demonstra que mesmo após a implementação de políticas de proteção feminina e da constante inclusão na pauta de debates questões de gênero, ainda assim, a desigualdade entre homens e mulheres na política, se mostra significativa. A ocupação das ruas, a conquista do mercado laboral, a presença no espaço público, a reserva de lugares nos parlamentos, todos conquistados paulatinamente, foram insuficientes para tornar possível uma paridade entre mulheres e homens na política.

A desigualdade que separa mulheres e homens nos cargos eletivos coloca a realidade brasileira atrás de muitos países que dão destaque à mulher no cenário político. Segundo dados da União Parlamentar, órgão vinculado às Nações Unidas, o Brasil ficou no $115^{\circ}$ lugar, em um ranking com 190 países (Relatório da União Interparlamentar, 2015). No levantamento de 2015, as mulheres somaram apenas $10,77 \%$ no Congresso Nacional brasileiro. Quando o assunto é presença feminina, ficamos atrás de países como Ruanda ( $1^{\circ}$ lugar, com $63,8 \%$ de mulheres), Bolívia $\left(2^{\circ}, \operatorname{com} 53,1 \%\right)$ Cuba $\left(3^{\circ}, \operatorname{com} 48,9 \%\right)$ e Suécia $\left(5^{\circ}\right.$, $\operatorname{com} 43,6 \%)$.

Dados do IBGE $^{3}$, de 2013, apontam que as mulheres representam 51,3\% da população brasileira. Ainda assim, a participação do público feminino na política é pequena e não corresponde à proporção de mulheres no país. Na Câmara dos Deputados, são apenas 51 deputadas federais, de um total de 513 parlamentares. No Senado, não muda muito: de 81 senadores, 13 são mulheres. Isso representa um total de apenas $10,77 \%$ de representantes femininas no Congresso Nacional.

A política de cota, no Brasil e no mundo, que reservou assento para as mulheres em parlamentos e nos cargos públicos, através de alterações no ordenamento jurídico, com objetivo de propiciar igualdade de gênero, nos países onde essas medidas foram aplicadas continua muito reduzido, apesar das políticas de cotas e reservas de assentos terem

\footnotetext{
${ }^{3}$ Instituto Brasileiro de Geografia e Estatística. É uma fundação pública da administração federal brasileira. Tem sede na cidade do Rio de Janeiro. Suas atribuições ligadas às geociências e estatísticas sociais, demográficas e econômicas, primordialmente, realiza censos e organiza informações neles obtidas, para suprir órgãos das esferas governamentais federal, estadual e municipal, e para outras instituições e o público em geral.
} 
possibilitado uma maior representação das mulheres, porém, muito longe de proporcionar equilíbrio entre a representação feminina em comparação à masculina.

Desta forma, perpassar os caminhos da política de gênero é tarefa imperiosa. O debate orienta duas discussões: a primeira, mostra as políticas governamentais que buscaram igualar sexo-gênero na representação política, pelos meios tradicionais, a exemplo das cotas, que se mostraram ineficientes e incapazes de reverter um quadro de desigualdade reinante em escala mundial, a despeito de tímido avanço; e, a segunda, propõe, a partir da uma educação política, instituir uma consciência coletiva que seja capaz de viabilizar, mediante o sufrágio popular, o almejado equilíbrio entre a presença feminina e a masculina na política.

Nesse contexto, o enfrentamento da discriminação estrutural existente na vida política brasileira, que historicamente excluiu a mulher da atividade pública, se mostra necessário. A dialética elege a Educação como projeto piloto capaz de viabilizar igualdade política entre mulheres e homens na política, como forma de conferir legitimidade democrática ao sistema.

Propõe-se, nessa toada, um modelo educacional de participação democrática que prepare o ser humano para uma consciência política de igualdade de gênero, de modo a permitir abertura de caminhos para representação política das mulheres, desconstituindo os estereótipos de gênero presentes na sociedade, como meio de promover e dar visibilidade a ações culturais feitas por mulheres. Por isso, é fundamental inserir o debate sobre a igualdade de gênero no espaço escolar e incentivar mudanças nas práticas pedagógicas.

Destaca a relevância da escola na formação de cidadãos ativos, protagonistas de uma democracia substantiva e livre de situações de opressão. Pedro Demo (1995) bem destaca essa necessidade: "Para que a população compreenda, finalmente, que a exclusão política e econômica das maiorias é injusta, historicamente produzida e mantida, necessitamos de uma escola pública que lhe mostre isto criticamente e instrumente-a adequadamente para a luta histórica".

Finaliza, com a advertência que o investimento em educação política torna-se imprescindível para construção de uma modelagem social com qualificação suficiente para o exercício de uma cidadania comprometida com políticas de ideias, sem rótulos e sem lutas entre mulheres e homens por espaço na sociedade, e que promova mudança cultural, com prospecto da reflexão crítica em que prevaleça a igualdade de gênero, onde mulheres e homens sejam solidariamente responsáveis pelo bem geral. Para subsidiar este estudo, foram realizados levantamento bibliográfico e análise de documentos. 


\section{DEMOCRACIA E A PARTICIPAÇÃO FEMININA}

A democracia é um processo em franco dinamismo e próprio de uma sociedade aberta e ativa, que disponibiliza ao seu povo a possibilidade de desenvolvimento integral, com livre participação política, condições de igualdade econômica, política e social (CANOTILHO, 1999). Nesse prisma, o processo democrático está em permanente construção, e, é por está em constante aprimoramento que sua análise não deve ser feita de forma anacrônica, devendo-se levar em consideração a sua época.

A construção de uma sociedade democrática percorre um longo e doloroso caminho de participação do povo, dos indivíduos e de setores da sociedade para ser erguida e responder aos anseios a que se propôs. A participação política do cidadão, como forma de intervir no processo de decisão, corolário de sua contribuição no exercício da soberania (direito de voto e igualdade de acesso aos cargos públicos), se apresenta, inegavelmente, como forma complementar imprescindível das demais liberdades (SARLET, 2007).

Para Bobbio (2002) a democracia não se refere só à ordem do poder público do Estado, mas deve existir em todas as relações sociais, econômicas, políticas e culturais. Começa na relação interindividual, passa pela família, a escola e culmina no Estado. Uma sociedade democrática é aquela que vai conseguindo democratizar todas as suas instituições e práticas.

A democracia não é apenas uma forma de governo, uma modalidade de Estado, um regime político, uma forma de vida. É um direito da Humanidade (dos povos e dos cidadãos). Democracia e participação se exigem, democracia participativa constitui uma tautologia virtuosa. Não há democracia sem participação, sem povo. O regime será tanto mais democrático quanto tenha desobstruído canais, obstáculos, óbices, à livre e direta manifestação da vontade do cidadão.

Há fortalecimento da democracia quando aumentam os espaços de participação política, assim entendida, o envolvimento de todos no processo decisório. Nessa toada, dentro de uma proposição participativa na aferição de uma democracia plena, surge à necessidade de se analisar as políticas de gênero, com reflexo direto na representação feminina nos postos de poder, considerando o número ínfimo de mulheres que participam de cargos no legislativo brasileiro.

A vida política brasileira, desde a colonização, tem se mostrado hierarquizadora sexo-gênero. Primeiramente, a mulher foi por muito tempo excluída do exercício da 
cidadania, quando lhe foi negado o direito de votar; empós, conquistado o direito de sufrágio, permanecem à margem da plena participação política, pois são sub-representadas nos postos de decisão política. Essa realidade, impõe ampla reflexão e estudo acerca da necessidade de uma presença equilibrada entre mulheres e homens nos órgãos de decisão, como forma de assegurar igualdade política entre mulheres e homens, de modo a conferir legitimidade ao sistema democrático.

Apesar de possuírem níveis de escolaridade superiores ao masculino e de estarem cada vez mais presentes no mercado de trabalho, em nenhum âmbito da vida social a participação de mulheres e homens é tão desigual como no exercício do poder. Seja em cargos eletivos, em postos de direção nos órgãos executivos ou no sistema judiciário, o poder ainda é predominantemente ocupado por homens. Somente no ano 2000, uma mulher ${ }^{4}$ tomou assento no órgão de cúpula do Poder Judiciário brasileiro.

Não obstante tenha sido um dos primeiros países da América Latina a conceder o sufrágio universal, o Brasil está entre as nações que apresentam a mais baixa representação política feminina no Ocidente ${ }^{5}$. Este cenário se repete em diversas nações tidas como desenvolvidas e com maior tradição democrática, como é o caso da França ${ }^{6}$. Convém registrar, interrupções na trajetória democrática do país por regimes ditatoriais que impediu o livre gozo político dos cidadãos, com impacto sobre a participação das mulheres.

A compreensão de inclusão da mulher no cenário político tem dimensão cultural, social e política e, conforme Feitosa (2009), um fator importante na transformação da visão feminina como sujeito ativo no processo legiferante seria o estudo do Direito sob uma perspectiva humanista: “A solução para que haja a transformação não é a integração e a incorporação, nesse sistema atual, mas a transformação para que possam 'fazer-se seres para si“" (FREIRE, 1987, p. 35).

A formação de uma cultura democrática como a sonhada pelo educador Pedro Demo (1995) nasce do conhecimento enquanto instrumento político de libertação. Ela permitirá o desenvolvimento dos potenciais de cada aluno-cidadão no meio social em que vive. Quem hoje poderá pensar a problemática social brasileira sem levar em conta o significado da escola nesse contexto?

\footnotetext{
${ }^{4}$ A ministra Ellen Gracie Northfleet é nomeada para integrar o Supremo Tribunal Federal.

${ }^{5}$ No Brasil as mulheres representam apenas $10,77 \%$ das vagas no Congresso Nacional, bem abaixo de vizinhos latino-americanos como Uruguai, Paraguai, Chile, Venezuela, Panamá, Peru e Colômbia. Vários Países menos desenvolvidos no mundo também estão a frente do Brasil, como tais, Jordânia, Síria, Somália, Indonésia, Iraque, Paquistão, Afeganistão, Tunísia, Emirados Árabes. A média da representação feminina nos parlamentos de países no Oriente Médio é de $16 \%$.

${ }^{6}$ No parlamento francês $26,6 \%$ das vagas são ocupadas por mulheres, que representa o $47^{\circ}$ lugar, no ranking do Relatório da União Inter-Parlamentar 2015.
} 
Essa política que hierarquiza sexo-gênero adotada no Brasil e em muitas partes do mundo, inibe o exercício de uma cidadania ativa no processo de construção da democracia. Ela reflete uma coletividade desprovida de opinião, mas apenas de sentimentos públicos sem articulação, flutuações sentimentais, não habituadas à participação política consistente, que só é exercida mediante convocação oficial por meio do voto. Para Sartori (1965), a democracia resumida às eleições não estimula o poder do povo de influenciar, transformando-o em produto, não em força motivadora do processo político, de modo que não há soberania popular quando o eleitor comum é convocado a decidir sobre questões acerca das quais ele não conhece.

Para Stuart Mill (2006), a participação política teria grande valor educativo, favorecendo o desenvolvimento moral e intelectual dos cidadãos, lhes proporcionando uma série de habilidades úteis a tomada de decisões. Quando o indivíduo se ocupa apenas de seus assuntos privados, limita o avanço de suas capacidades para uma ação pública responsável. ${ }^{7}$

Eleni Varikas (1996) em debate por paridade entre homens e mulheres em órgãos deliberativos, afirma que a celeuma em torno dessa igualdade revela a incapacidade da democracia representativa integrar a metade dos cidadãos ao sistema político, apesar de ter sido instituído a igualdade de direitos e o sufrágio universal. Defende um sistema democrático por excelência, em que a presença das mulheres e de grupos socialmente excluídos, tenha espaço nas instancias de decisão política, compatível com a sua representação populacional. Percentual reduzido de mulheres entre os representantes do povo é reflexo do modelo excludente do sistema político em si mesmo. Os tímidos avanços da participação feminina perante os órgãos de poder se prestam, unicamente, para minimizar os efeitos deletérios causado por um sistema de democracia desacreditado, com o propósito de moderar o "défícit democrático".

\section{A BAIXA REPRESENTATIVIDAdE DAS MULHERES NOS ÓRgãos DE REPRESENTAÇÃO POLÍTICA, APESAR DOS AVANÇOS ALCANÇADOS}

O direito das mulheres de participar da esfera pública, nas instâncias de decisão, notadamente em postulação eletiva, foi conquistado através de um longo processo de lutas, 


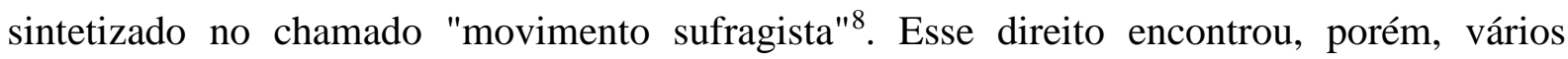
obstáculos de ordem material - tempo, dinheiro, subordinação formal à autoridade paterna ou conjugal - assim como de ordem subjetiva - a ideia de que política é coisa de homens, restrições familiares, culpas -, além da realidade enfrentada: os lugares, cargos, vagas para a disputa política já estavam ocupados e estruturados segundo critérios, dinâmicas, valores e referenciais masculinos.

Essas restrições permaneceram normatizadas até recentemente. É o caso da Suíça, que só concedeu o direito de voto às mulheres da década de 1970. A França, país considerado o berço da democracia moderna, surpreendentemente só veio a admitir o direito de voto às mulheres em 1944. Com efeito, ao lado dos condicionantes socioeconômicos e culturais de cada país, há imposições históricas e políticas que necessitam ser consideradas ao se analisar a situação das mulheres na política institucional. Em consequência dessa exclusão, a presença feminina nos cargos de decisão política, ainda é muito pequena se comparada à masculina.

Devido à pressão organizada pelos movimentos de mulheres, o acesso aos cargos de decisão passou a ser objeto de atenção de governos e organismos internacionais, que resultou em assinaturas de compromissos e programas oficiais de estímulo à participação política feminina. Muitos desses tratados não saíram do papel. É, fato, porém, que o reconhecimento público dessa marcha contribuiu para dar maior visibilidade à sub-representação feminina, e tornar a questão afeta ao sistema democrático, descolada da esfera privada e individual das mulheres.

A década de 1990 foi bastante favorável à participação política feminina no mundo9 . Houve aumento importante no percentual de presença feminina nos cargos políticos. $\mathrm{O}$ avanço é atribuído à alguns fatores, notadamente: o impulso conferido pela IV Conferência Mundial da $\mathrm{ONU}^{10}$ sobre a Mulher, que deu importância a equidade de gênero nas instâncias decisórias; e, adotou políticas de ação afirmativa - as cotas - que estimulou à inserção feminina nas competições eleitorais.

Ao contrário de outros setores como os da educação e do trabalho, esse avanço ainda está longe de representar uma situação próxima do equilíbrio entre os sexos (COSTA; BELTRÃO, 2008). Os homens continuam sendo amplamente majoritários na política.

\footnotetext{
${ }^{8}$ Foram diversas campanhas realizadas a partir de meados do século XIX para garantir às mulheres da Inglaterra e dos Estados Unidos algo então inédito para elas: o sufrágio, direito de votar em eleições políticas.

${ }^{9}$ Os países da América Latina e da Europa adotaram cotas eleitorais mediante leis que prevêem a reserva de vagas para cada sexo ou especificamente para as mulheres nas candidaturas eleitorais dos partidos. A Argentina foi o país pioneiro no mundo em legalizar o mecanismo das cotas, ao aprovar a "Ley de Cupos", em 1991.

${ }^{10}$ Realizada em Pequim em 1995.
} 
Dados da União Interparlamentar ${ }^{11}$ apontam reduzida presença de mulheres ocupantes de funções políticas. Atualmente a média mundial é de $22 \%$ de mulheres nas assembleias nacionais (Relatório da Organização das Nações Unidas sobre os Objetivos de Desenvolvimento do Milênio - ODM, 2015), constituindo enorme desigualdade em comparação com a presença masculina. Essa realidade, que é antiga e crônica, fez as Nações Unidas, ainda no ano 2000, incluir em sua Declaração de Objetivos de Desenvolvimento do Milênio $(\mathrm{ODM})^{12}$, uma política de "Promoção de Igualdade de Gênero e Capacitação das Mulheres", tendo como meta, o avanço na pretensão de igualar homens e mulheres nos órgãos de decisão política.

No ano de 2015, as Nações Unidas, emitiu o resultado final ${ }^{13}$ desse projeto, com todos os dados obtidos, suas conclusões, e trouxe detalhado e aprofundado estudo sobre o alcance das 8 metas que haviam sido propostas naquele propositivo documento. Intitulado Relatório dos Objetivos de Desenvolvimento do Milênio 2015, o atestado mostra que o esforço de 15 anos produziu o mais bem sucedido movimento de combate à pobreza e as demais proposições da história contemporânea. Contudo, em relação ao objetivo 3 "Promoção de Igualdade de Gênero e Capacitação das Mulheres" -, o relatório apesar de destacar progressos para a igualdade das mulheres na representação política nas últimas duas décadas, reconhece continuar lacunas e lentidão no processo de igualização sexo-gênero, com sugestão que o tema continue nos objetivos da agenda para o desenvolvimento pós-2015.

Os números colhidos no relatório da ODM são assim sintetizados: desde 1995, quando foi adotada a Plataforma de Ação de Pequim sobre a capacitação das mulheres, a proporção média global de mulheres no parlamento quase que duplicou, com aumento de $11 \%$ em 1995 para $22 \%$ em janeiro de 2015. As mulheres no parlamento ganharam terreno em quase $90 \%$ dos 174 países para os quais existem dados para 1995-2015. O número de câmaras únicas ou baixas de parlamentos onde as mulheres ocupam mais de $30 \%$ dos assentos aumentou de 5 para 42, enquanto que aquelas onde ocupam mais de $40 \%$ aumentaram de 1 para 13. Em janeiro de 2015, existiam quatro países com mais de $50 \%$ de assentos

\footnotetext{
${ }^{11}$ A União Interparlamentar (UIP - ou IPU, em inglês) é uma organização internacional dos parlamentos dos Estados soberanos, que tem como objectivo mediar os contatos multilaterais dos parlamentares.

${ }^{12}$ Declaração lançada em setembro do ano 2000 pelas Nações Unidas em que líderes mundiais, refletindo e baseando-se na década das grandes conferências e encontros das Nações Unidas, reuniram-se em sua sede, em Nova York, e adotaram a Declaração do Milênio da ONU. Com esse documento, as Nações se comprometeram a uma nova parceria global para reduzir a pobreza extrema, em uma série de oito metas, com um prazo para o seu alcance em 2015 que se tornaram conhecidos como os Objetivos de Desenvolvimento do Milênio (ODM).

${ }^{13}$ A Declaração estabeleceu prazo de 15 anos para o alcance das metas. Esse encerrou em junho de 2015, data final das colheitas dos dados estatísticos lançados do relatório final.
} 
parlamentares ocupados por mulheres, e em Ruanda, as mulheres detêm mais de $60 \%$ destes assentos (Relatório da Organização das Nações Unidas sobre os Objetivos de Desenvolvimento do Milênio - ODM, 2015).

Esses dados, considerados progressivos, são também partilhados de forma mais igualitária entre as regiões. Em 1995, a Europa dominava a classificação dos 10 primeiros locais do mundo com mulheres nos parlamentos. Em janeiro de 2015, 4 dos 10 primeiros países encontravam-se na África Subsariana, enquanto o Continente Americano e a Europa tinham cada um 3 países entre os 10 primeiros. Os maiores ganhos na representação de mulheres durante os últimos 20 anos verificaram-se em Ruanda, com um aumento de 60 pontos percentuais, Andorra com 46 pontos percentuais, e Bolívia com 42 pontos percentuais. O número de homens nos parlamentos também diminuiu, de 10 para 5.

Ainda é de se destacar que o progresso nas posições de liderança foi lento. Apenas $16 \%$ dos líderes congressistas - presidentes de parlamentos - são mulheres, enquanto as mulheres representam $18 \%$ de todos os ministros de governos no planeta, um aumento de apenas 4 pontos percentuais desde 2005 (Relatório da Organização das Nações Unidas sobre os Objetivos de Desenvolvimento do Milênio - ODM, 2015).

No Brasil, apesar de pouquíssimos avanços, há muito a conquistar nesse tema. Dos assentos da Câmara e do Senado 10,77\% são ocupados por mulheres. Num ranking criado pela União Inter-Parlamentar (Relatório da União Inter-parlamentar, 2015), o Brasil ocupa a $115^{\mathrm{a}}$ posição numa lista de 190 países ordenados segundo a proporção de mulheres eleitas para o parlamento, bem abaixo de diversos de nossos vizinhos latino-americanos (como Uruguai, Paraguai, Chile, Venezuela, Panamá, Peru e Colômbia) e de vários países menos desenvolvidos (como Jordânia, Síria, Somália, Indonésia, Iraque, Paquistão, Afeganistão, Tunísia, Emirados Árabes).

Os dados coletados apontam inexorável conclusão: a presença feminina nos cargos de representação política continua deficitária no mundo inteiro, inclusive na comunidade européia, em que sua nota nesse quesito sempre superou o parâmetro mundial que, inclusive, é muito baixa se confrontada com a população feminina do planeta. Revelador, não se perca de vista, a lentidão com que se deu o progresso apontado. Hipóteses excepcionais de crescimento acelerado foram constatadas em Ruanda e Bolívia, onde os respectivos percentuais feminino na representação política são acima de 50\%, superando evidentemente o padrão médio mundial que é de $20 \%$, em franca desproporção entre a média das mulheres no mundo com a média feminina nos cargos de representação política.

\section{Instrumentos de ações afirmativas}


A Declaração Universal dos Direitos Humanos, promulgada em 1948, e a Convenção da Assembléia Geral das Nações Unidas sobre os Direitos Políticos da Mulher, de 1954, foram pioneiras no campo legislativo internacional garantidores da igualdade política entre homens e mulheres. Referidos atos normativos lançaram aos Estados subscritores a proposição de igualdade, sem qualquer distinção, entre mulheres e homens, em avanço aos tipos de direitos, inclusive políticos. Com isso, deu-se a largada na difícil missão de promover igualdade de gênero, na tentativa de afastar os óbices que enfrentavam as mulheres em sua exclusão política. Inexistia qualquer tipo de política ou movimento organizado fomentador da presença de mulheres nas decisões de poder, sendo necessário um alargamento dos direitos políticos.

Doravante, em 1979, as Nações Unidas aprova documento que prevê medidas afirmativas e abertura de agenda voltada com exclusividade para o combate da discriminação e à promoção da eqüidade entre mulheres e homens. A Convenção sobre a Eliminação de Todas as Formas de Discriminação Contra a Mulher, aprovada em 18 de dezembro daquele ano, subscrita inicialmente por 20 países, em poucos anos já contava, em setembro de 2007, com adesão de 185 países, o Brasil era um dos signatários.

A IV Conferência Mundial sobre a mulher, realizada em Pequim, foi, também, um marco importantíssimo de propagação dos direitos da mulher, comandado pelas Nações Unidas. No documento aprovado reiterou em uma escala mundial e com grande visibilidade o direito de participação ativa da mulher na trajetória governamental do seu país, enfatiza a autonomia feminina e a melhoria da condição social, econômica e política da mulher como fundamento de existência de uma modelação de governar com sustentação necessária para criar as condições de desenvolvimento nas áreas da existência. A carta de Pequim é explicita no ideal de igualdade de participação da mulher e do homem na adoção de decisões, e afirma que essa meta atingirá uma equidade com reflexo direto na composição da sociedade.

O olhar do mundo se voltou a Pequim quando, editado o documento, defendeu-se, em seu parágrafo 181 da Plataforma de ação, que a "participação igualitária da mulher na tomada de decisões constitui não só uma exigência básica de justiça ou democracia, mas também pode ser considerada uma condição necessária para que os interesses da mulher sejam levados em conta. Sem a participação ativa da mulher e a incorporação do ponto de vista próprio da mulher em todos os níveis do processo da tomada de decisões não se poderá conseguir os objetivos de igualdade, desenvolvimento e paz". 
O parágrafo 187 da Plataforma prevê a adoção de ação afirmativa em favor das mulheres na política. Outras medidas incentivadoras da igualdade de gênero estão no documento, como tais destacam-se: a) buscar uma representatividade na perspectiva de igualar mulheres e homens no campo de atuação dos governos e na participação da coisa pública; b) fomentar os partidos políticos a incorporar em seus órgãos estatutários e em seus ideais políticos o direito das mulheres alçar postos públicos eletivos proporcionalmente com homens; e d) fazer estudo que possa detectar as diferenças existentes entre mulheres e homens nos sistemas eleitorais acerca da participação das mulheres, comparando-a com os homens, para, doravante fazer as adaptações necessárias, mediante reformulação dos sistemas.

Mais recentemente, no ano 2000, a Assembléia Geral das Nações Unidas, editou um outro documento denominado "A Declaração de Objetivos do Milênio", que tratou sobre os objetivos a serem alcançados pelos países membros até o ano de 2015, ocasião em que reafirmou todos os compromissos assinados em proposições anteriores acerca da proteção a mulher, onde defendeu: 1) a criação de regimes democráticos e a observância plena de todos os direitos inerentes a humanidade, notadamente das minorias; e 2) a implementação da Convenção sobre a Eliminação de Todas as Formas de Discriminação contra a Mulher, de 1979.

Mas não é só. Mecanismo de vital importância instituída mundo afora na busca pela igualdade de gênero, são as cotas eleitorais. Elas são regras existentes em uma determinada organização que asseguram ao sexo feminino o direito de ocupação de uma determinada fração de vagas ou postos existentes. Sua finalidade é ampliar a presença feminina nos centros de decisões - governos, parlamentos e conselhos - por eleição ou indicação. Para os defensores da existência de cotas, a causa da baixa presença feminina na política tem fundamento nas práticas excludentes dos partidos e do sistema político (DAHLERUP, 2005: 141).

A política de cotas sugere controvérsia. Essa idéia de resguardar espaço para as mulheres em organizações de poder está em constante conflito com outras noções elementares de direito, como se pode ver do discurso sobre a justiça e a competência pessoal, e ainda, considerada a ideia de individualismo.

Drude Dahlerup (2005) elencou argumentos a favor e contra as cotas eleitorais. Para os defensores: (a) além de que não discriminam, compensam os obstáculos que impedem as mulheres chegar as instâncias de poder; (b) enquanto cidadãs, elas tem igual direito representação; (c) somente as mulheres conseguem representar a si mesmas; (d) as cotas limitam os partidos políticos em nomear apenas homens; (e) é consenso mundial o objetivo de 
representação política das mulheres, como firmado na Plataforma de Pequim, em 1995, com propósito de eliminação de todas as formas de discriminação contra a mulher; (f) as mulheres enquanto representam cerca de 50 por cento da população mundial, ocupam apenas 22 por cento das vagas nos parlamentos ao redor do globo.

Em giro diverso, a corrente contrária a política de cotas, aponta: (a) são violadoras do princípio da igualdade de oportunidades, ao assegurar a mulher tratamento preferencial; (b) subverte a lógica da representação política, escolhe categorias sociais em detrimento do ideal político e plataforma partidária; (c) afrontam a liberdade democrática que confere as eleitoras ampla liberdade de escolha, sem imposição de restrições; (d) parte dos candidatos aos cargos eletivos, serão sufragados a partir do sexo, sem importar seus ideais políticos; (e) as cotas institui conflitos dentro sociedade nas organizações partidárias; e (f) cotas para mulheres, poderá sugerir demandas no mesmo sentido por outros grupos supostamente excluídos (negros, índios, e etc), o que poderá resultar em uma política de interesses de grupos.

O certo é que, em meio às correntes favoráveis e contrárias, a política de cotas se instalou em parte do planeta, com exemplos de sucesso, mas também de fracassos. No espectro mundial revela seu nascedouro na Argentina, que foi o primeiro país a legiferar sobre essa política feminina. Sua experiência exitosa e o incentivo da IV Conferência sobre a mulher de Pequim (1995), que influenciou o implemento de ideais de busca para garantir o acesso igualitário e a plena participação das mulheres nas estruturas de poder e tomada de decisões (AQUINO DE SOUZA, 2010) foram a motivação para que outras nações, notadamente as democráticas, abrissem agenda de discussão sobre a adoção de cotas eleitorais de gênero.

$\mathrm{Na}$ Europa e por toda América Latina a política de cotas eleitorais de gênero ganhou relevo, de sorte que, a maioria dos países adotou em seu ordenamento jurídico, previsão de reservas eleitorais, fosse para preenchimento por sexo ou diretamente reservada para as mulheres. Esse regramento é usado em um número cada vez maior de países em todas as regiões do mundo. Hoje mais de 40 países possuem legislações nacionais de cotas e mais de 160 partidos políticos adotam-nas voluntariamente para assegurar um mínimo de mulheres incluídas como candidatas nas eleições (BALLINGTON, 2007) ${ }^{14}$.

\footnotetext{
14 Informações extraídas da apresentação de Julie Ballington, pesquisadora do Inter-Parliamentary Union (IPU), intitulada Implementing Special Measures:Global trends. A apresentação fez parte do ciclo de palestras do Seminário "Trilhas do Poder das Mulheres: Experiências Internacionais em Ações Afirmativas" realizado nos dias 19 e 20 de junho de 2007 em Brasília.
} 
O Brasil inaugurou a legislação sobre cotas eleitorais na Lei n. 9.100/95, que estabeleceu o preenchimento de vagas para a disputa nas eleições municipais de 1996, fixando que $20 \%$ das candidaturas seriam reservadas as mulheres. Em setembro de 1997, foi aprovada a Lei eleitoral n. 9.504/97, que trouxe previsão de reserva de um mínimo de 30\% e um máximo de $70 \%$ para as candidaturas de cada sexo, nas eleições para a Câmara dos Deputados, Câmara Legislativa, Assembléias Legislativas dos Estados e Câmaras Municipais, contemplando as eleições proporcionais de todo país, mas excluindo as eleições regidas pelo sistema majoritário. Esta lei encontra em pleno vigor na presente data.

A experiência de política de cotas no Brasil não foi exitosa, pois a legislação que a instituiu não conseguiu alterar significativamente este fato de caráter histórico e cultural, embora seja inconteste seu papel de dar maior visibilidade à situação de exclusão da mulher na política. No resto do mundo os números apontam em sentido similar. Contudo, percebeu-se que a conquista de um espaço maior para a mulher na política demanda mais que a fixação de um percentual a ser cumprido por partidos políticos. Não se trata tampouco de vencer uma discriminação contra a mulher. O caminho a ser percorrido passa pela produção de capital político entre as mulheres, entendido aqui como a capacidade de se fazer reconhecida como ser político capaz de tomar decisões nas diferentes esferas do poder. Neste sentido ressalta-se a importância de ações capazes de permitir às mulheres expor a sua competência na gestão dos interesses da sociedade.

\section{EDUCAÇÃO COMO MEIO PARA ALCANÇAR UM EQUILIBRO SEXO-GÊNERO}

Em todo estudo, um assunto foi dominante: o debate por paridade sexo-gênero nos órgãos de decisão - legislativo, executivo e administração pública - e que há uma desproporção entre mulheres e homens nos postos eletivos, gerando um déficit enorme na representação feminina em comparação à masculina. Demonstrou-se a partir de dados oficiais, que diversas políticas buscando a sonhada igualdade de gênero no campo da representação política, mostrou-se sem resolutividade significativa, permanecendo um fosso abissal entre mulheres e homens nos órgãos de representação política, considerada a média mundial. Perspectivas apontam a possibilidade de que as desigualdades permaneçam latentes e com pouca alteração a longo prazo.

Questiona-se que papel do Estado promoveria a correção dessas desigualdades, e buscaria efetivar uma política capaz de promover equilíbrio na representação política entre 
mulheres e homens, e um desenvolvimento equitativo, minimizando o desequilíbrio existente sexo-gênero nas relações políticas. O que deve ser feito?

A participação feminina na atividade política brasileira vem sendo considerada em descompasso com representação populacional, e tem distanciado uma grande parte da população do seu exercício pleno de democracia material, distorcendo o fundamento da Constituição Federal de 1988 que é a dignidade da pessoa humana. Para Varikas (1996) "a minorização política de uma categoria majoritária de cidadãos constitui o sinal mais visível e mais evidente dos limites da democracia real”.

É inevitável a indagação: o que fazer? Os modelos experimentados se mostraram ineficazes. Qual o modelo ideal? Bercovici (2011, p.575) indica que o texto constitucional encontra-se estruturado e planificado no ideal transformador da sociedade, com previsão de um projeto de desenvolvimento. Nesse turbilhão de inquietações, Comparato (1985, p. 403) direciona o rumo a ser seguido: a expressão normativa constitucional, isoladamente considerada, se mostra deficiente. Ela não cria movimento, nem o impulsiona. Nesse viés, outra não é a conclusão, senão entender que a revolução só será concretizada pela população consciente de direitos e deveres de cidadania.

"Somente uma população consciente da sua cultura, da sua história, dos valores e das tradições é capaz de se posicionar como sujeito de direitos e deveres" (POMPEU, 2009, p. 139). "Há de se acreditar que o distanciamento, por parte da população, do Estado e de suas funções e a ausência de ações que defendam o interesse público têm como razão a falta de educação" (POMPEU, 2005, p.19).

A grande revolução é a educação: ela constitui base estrutural de formação do individuo, com direta influência em todos os setores da vida humana. Educar é um ato que visa à convivência social, a cidadania e a tomada de consciência política. A educação escolar, além de ensinar o conhecimento científico, deve assumir a incumbência de preparar as pessoas para o exercício da cidadania. Entendida esta como o acesso aos bens materiais e culturais produzidos pela sociedade, e ainda significa o exercício pleno dos direitos e deveres previstos pela Constituição da República.

O caminho é explicito; o vértice direcional é um só: educar-se para desenvolver-se. É Nessa toada que Pedro Demo (1995) mostra que a formação de uma cultura democrática nasce do conhecimento enquanto instrumento político de libertação. A educação para a cidadania pretende fazer de cada pessoa um agente de transformação. Isso exige uma reflexão que possibilite compreender as raízes históricas da situação de miséria e exclusão em que vive 
boa parte da população. A formação política, que tem no universo escolar um espaço privilegiado, deve propor caminhos para mudar as situações de opressão. Muito embora outros segmentos participem dessa formação, como a família ou os meios de comunicação, não haverá democracia substancial se inexistir essa responsabilidade propiciada pelo ambiente escolar.

O papel transformador da educação é o vetor para as conquistas da sociedade. É a chave que abre a porta para o progresso econômico e social. Evidentemente não é investimento de retorno imediato; seus frutos são parcimoniosos. Prevalecer á visão tradicional de governança o fosso entre gênero feminino e sua representação nos órgãos eletivos de decisão se manterá. A revolução transformadora dificilmente partirá dos governos. Caberá à sociedade consciente, através de sua participação ativa nos processos políticos viabilizar essa mudança.

A discussão política promovida em decorrência da participação eleitoral, classes populares sairiam de uma compreensão limitada dos trabalhos repetitivos e concentrados da fábrica para uma compreensão mais ampla de conexão dos eventos distantes e o seu interesse pessoal, estabelecendo relações com cidadãos diversos daqueles com os quais mantém relações cotidianas, tornando-se, assim, membro consciente de uma comunidade (Bobbio, 1986). Isso criaria uma cultura política de educação para a cidadania.

A educação para a cidadania política deverá formar o cidadão, homem ou mulher, políticos ou qualquer indivíduo humano, para o argumento ético sobre a possibilidade de uma comunidade ideal não ser aquela em que a mulher lute pelos interesses femininos e que os homens lutem pelos interesses masculinos, mas o importante é o compartilhamento e o debate em todos os homens e todas as mulheres comprometidos solidariamente com a vontade geral.

Países que adotaram políticas de paridade de gênero, pilotadas por modelo de educação política, mostraram grande eficácia. O Exemplo sedutor é Ruanda, $1^{\circ}$ lugar no ranking mundial de representação feminina no Parlamento, com 63,8 \% dos assentos na Câmara dos Deputados e 38,5 \% de assentos no Senado (Relatório da União InterParlamentar, 2015). Nadine Gasman, Representante do Escritório da ONU Mulheres no Brasil, explica o processo de mudança em Ruanda (on line, 2015):

\footnotetext{
"A área de educação incorporou a igualdade de gênero nas suas matrizes de formação. Houve aumento no acesso da população à saúde e queda significativa da mortalidade infantil. As mulheres estão mais presentes no serviço público e também passaram a ser titulares de terras. Em amplos setores, as mulheres alargaram a sua participação, conquistando voz e poder de decisão que colaboraram para o país se reconstituir num dos casos mais trágicos de guerra no mundo."
} 
A governança em Ruanda adota o seguinte lema: "O gênero agora é parte do nosso pensamento político. Nós admiramos todos aqueles que compõem nossa população, pois nosso país já viu o que significa excluir um grupo" ${ }^{15}$. Constata-se, a partir desta afirmação, a exata dimensão de que, a educação política é o império da inclusão plena das políticas de gênero.

\section{CONCLUSÃO}

Conclui-se, portanto, que o Brasil, a despeito de possuir de $51,3 \%$ de população feminina, sua representação política é muito pequena e não corresponde à proporção de mulheres no país. No Congresso Nacional apenas $10,77 \%$ dos assentos são de representação feminina. Essa realidade coloca o Brasil no $115^{\circ}$ lugar no mundo quando o assunto é presença feminina e paridade de gêneros nos órgãos de decisão. Ficamos atrás de países como Ruanda, Bolívia, Cuba, Senegal e Suécia.

Essa é uma realidade mundial. A presença feminina nos cargos de representação política é deficitária no mundo inteiro, apesar de avanços tímidos. As políticas de gênero não cumpriram seu papel e a desproporção entre mulheres e homens nos postos eletivos, se manteve, muito embora a debate tornou-se visível e faz parte da agenda internacional.

Com isso um alvo certo é atingido: a democracia. A celeuma em torno da paridade sexo-gênero no Brasil revela a incapacidade da democracia representativa integrar a metade dos cidadãos ao sistema político, ainda que se tenha instituído a igualdade de direitos e o sufrágio universal. O fundamento do sistema democrático é distorcido, em função da quebra do exercício da democracia material. Para Varikas (1996) a minorização política de uma categoria majoritária de cidadãos constitui o sinal mais visível e mais evidente dos limites da democracia real.

A resolução desse dilema só se dará com construção de uma consciência de cidadania, partir de um modelo de educação política, que qualifique homens e mulheres, comprometidos e igualmente solidários com a vontade geral.

\section{REFERÊNCIAS}

${ }^{15}$ John Mutamba é integrante do Ministério de Desenvolvimento de Gênero e Mulheres de Ruanda. 
AQUINO DE SOUZA, Cristiane. Cotas eleitorais para a igualdade de gênero: uma perspectiva jurídico-constitucional. Anuario de Derecho Constitucional Latinoamericano, ano XVI, 2010, p. 239-253.

A política da presença para as mulheres. In: AQUINO DE SOUZA, Cristiane (org). Democracia, igualdade e liberdade: Perpectivas jurídicas e filosóficas. Rio de Janeiro: Editora Lúmen Júris, 2015, p. 31-63.

BALLINGTON, Julie. Implementing Special Measures: Global trends. Trabalho apresentado no Seminário “Trilhas do Poder das Mulheres: Experiências Internacionais em Ações Afirmativas”. Brasília, 2007.

BERCOVICI, Gilberto. Política econômica e direito econômico. Pensar: Revista do Curso de Direito da Universidade de Fortaleza, v. 16, n. 2, 2011, p. 562-588. Disponível em: <http://www.unifor.br/images/pdfs/Pensar/v16n2_artigo6.pdf>. Acesso em: 13 nov. 2013.

BOBBIO, Norberto. O futuro da democracia. Uma defesa das regras do jogo. Tradução: Marco Aurélio Nogueira. Rio de Janeiro: Paz e Terra, 1986.

. A Era dos Direitos. Rio de Janeiro: Ed. Campus, 1992.

. Igualdade e Liberdade. Rio de Janeiro: Ediouro, 1996.

Teoria geral da política. Rio de Janeiro: Campus, 2002.

CANOTILHO, José Joaquim Gomes. Direito constitucional e teoria da constituição. $3^{\text {a }}$ ed. Coimbra: Almedina, 1999.

COMPARATO, Fábio Konder. Um quadro institucional para o desenvolvimento democrático. In: JAGUARIBE, Hélio et al. Brasil, sociedade democrática. Rio de Janeiro: José Olympio, 1985.

COSTA, Thiago Cortez; BELTRÃO, Kaizô Iwakami. Cotas e mulher na política: avaliando o impacto de variáveis institucionais e socioeconômicas sobre a elegibildade feminina. Disponível em: 
http://www.abep.nepo.unicamp.br/encontro2008/docsPDF/ABEP2008_991.pdf>.Acesso em: 12 nov. 2010.

DAHLERUP, Drude. Increasing Women's Political Representation. In BALLINGTON, Julie e KARAM, Azza. Women in Parliament: Beyond Numbers. Stockholm: IDEA, 2005.

DEMO, Pedro. Cidadania Tutelada e Cidadania Assistida. Campinas: Autores Associados, 1995.

FEITOSA, Maria Luiza P. de A. M. O currículo de direitos humanos no ensino superior e na Pós-graduação. Espaço do Currículo, v. 2, n. 2, p.98 - 114, set 2008-mar 2009. Disponível em: http://www.dhnet.org.br/direitos/militantesqmaluizalencar/mluiza_curriculo_dhensino_superior.p df Acesso em: 22 out 2015.

FREIRE, Paulo. Pedagogia do Oprimido. 5. Ed. RJ: Paz e Terra, 1978.

GADOTTI, Moacir. A educação contra a educação. Rio de Janeiro: Paz e Terra, 1981.

LAFER, Celso. A Reconstrução dos Direitos Humanos: Um diálogo com o pensamento de Hannah Arendt. São Paulo: Cia das Letras, 1988

MILL, John Studart. Considerações sobre o Governo Representativo. Coleção Grandes Obras do Pensamento Universal - 56. Trad. Débora Ginza e Rita de Cássia Gondim. Ao aulo: Editora Escala, 2006.

MILES. Rosalind. A história do mundo pela mulher. Rio de Janeiro: Casa Maria Editorial/LTC, 1989.

OLIVEIRA, Manfredo Araújo de. Educação, Autonomia e Direito in Ética, Direito e Democracia. $2^{a}$ Ed. São Paulo: Ed. Paulus, 2010. 
ONU - Relatório da Organização das Nações Unidas sobre os Objetivos de Desenvolvimento do Milênio 2015. Disponível em: https://www.unric.org/pt/images/stories/2015/PDF/MDG2015_PT.pdf. Acesso: em 30/11/2015.

PERUZZO, Cecília M. K. Comunicação nos movimentos populares: a participação na construção da cidadania. Petrópolis: Vozes, 1998.

POMPEU, Gina Vidal Marcílio. Direito à educação - controle social e exigibilidade judicial. Fortaleza: ABC Editora, 2005.

Atores do desenvolvimento econômico e social do século XXI/Gina Vidal Marcílio Pompeu (organizadora). Fortaleza: Universidade de Fortaleza, 2009.

SANTOS, Sidney Francisco Reis do. Mulher: Sujeito ou Objeto de sua própria história? Um olhar interdisciplinar na história dos direitos humanos das mulheres. Florianópolis: OAB/SC Editora, 2006.

SARLET, Ingo Wolgand. A eficácia dos direitos fundamentais. $7^{\mathrm{a}}$ ed. Porto Alegre: Livraria do Advogado, 2007.

SARTORI, Giovani. Teoria da Democracia. Trad. Francisco M. da Rocha Filho e Osvaldo Blois. Rio de Janeiro: Editora Fundo de Cultura, 1965.

TOSCANO, Moema; GOLDEMBERG, Miriam. A revolução das mulheres: um balanço do feminismo no Brasil. Rio de Janeiro: Revan, 1992.

VARIKAS, Eleni. Refundar ou Reacomodar a Democracia? Reflexões críticas acerca da paridade entre os sexos. in Revista de Estudos Feministas, v. 4, n. 1. Rio de Janeiro: IFCS/UFRJ e PPCIS/UERJ, 1996. 